\title{
COMMENTARY
}

\section{Tight glycemic control: what do we really know, and what should we expect?}

\author{
Stanley A Nasraway Jr* and Rishi Rattan \\ See related research by Chase et al., http://ccforum.com/content/14/4/R154
}

\begin{abstract}
Tight glycemic control has engendered large numbers of investigations, with conflicting results. The world has largely embraced intensive insulin as a practice, but applies this therapy with great variability in the manner of glucose control and measurement. The present commentary reviews what we actually know with certainty from this vast sea of literature, and what we can expect looking forward.
\end{abstract}

In the previous issue of Critical Care, Chase and colleagues present retrospective, historically controlled data from 784 critically ill patients treated with tight glycemic control (target glucose, 4 to $6 \mathrm{mmol} / \mathrm{l}$ ) using the Specialised Relative Insulin and Nutrition Titration (SPRINT) protocol [1]. They report achieving faster resolution of organ failure. This observation dovetails with the Leuven I trial [2] and early studies [3,4] that first showed reductions in the incidence of renal and respiratory failure, but conflicts with other more recent trials demonstrating no difference in organ failure when using intensive insulin [5-10].

The main advantages of SPRINT are that the protocol aims for relatively strict euglycemia, the protocol is conservative in application, the protocol maintains euglycemia with less variability, the protocol concomitantly adjusts for caloric intake using a handheld device protocol for insulin dosing, and the protocol requires frequent blood glucose monitoring. The first report on SPRINT indicated lower hospital mortality rates and less hypoglycemia in long-stay protocol patients [11]. What does this mean for the reader and bedside clinician in the intensive care unit (ICU)?

*Correspondence: Snasraway@tuftsmedicalcenter.org

Department of Surgery, Tufts Medical Center, 750 Washington Street, Box 4630, Boston, MA 02111, USA
The Leuven I study unleashed a torrent of skepticism, excitement and investigation into tight glycemic control [2]. Google searches for 'tight glycemic control' and 'intensive insulin' produce 80,900 and 334,000 results, respectively. After entering a new decade, where are we? There is a great deal that we do not know, in part because this field of discovery has been disadvantaged by inconsistencies in research methodology. Among differences in the studies are case-type selection, targeted ranges of blood glucose, inconsistency in the frequency of blood glucose monitoring, variability in the accuracy of glucometer devices used, variability in the methods used to define euglycemia, whether insulin dosing was driven by paper protocol or software algorithm, and nonstandardization in caloric intake.

Starting with the Leuven I trial, all of the prospective studies conducted to date are vulnerable to significant methodologic criticisms. We also really have no conclusive understanding of the biologic plausibility to explain how intensive insulin would decrease death or organ failure or nosocomial infection - is it through antiinflammatory pathways, or because insulin is a vasodilator that may increase microperfusion, or by other unrealized mechanisms of action? In some ways, the scientific evolution of this field resembles that of sepsis research from 1985 to 2005, in which the study of antiinflammatory compounds was severely hindered by lack of standardization in the total treatment for patients with severe sepsis, with too many confounding and uncontrolled variables [12].

After all of these studies, what do we actually know? What are the consistent threads? The following summarizes what we know with certainty.

First, hyperglycemia is toxic. Falciglia and colleagues convincingly showed in an analysis of 259,040 ICU patients that hyperglycemia (glucose $>6.1 \mathrm{mmol} / \mathrm{l}$ ) was associated with mortality independent of illness severity, type of ICU or length of stay [13]. Consistent with the findings of others, the two-thirds of patients who are nondiabetic benefit more from insulin than do diabetic patients. 
Hypoglycemia is also lethal. An incidental and constant observation from many studies is that severe hypoglycemia (glucose $<2.2 \mathrm{mmol} / \mathrm{l}$ ) in a population of patients by logistic regression is associated with a sixfold increase in death [14]. It would not be surprising to find with additional study that even mild hypoglycemia has longlasting but subtle neurologic consequences that are not clinically evident or measured.

Third, critically ill patients typically sustain wide deviations in blood glucose, even with insulin administration [15]. Restricting the blood glucose within a target range in a hypermetabolic patient with changing gluconeogenic drivers in a 24-hour day is enormously challenging, frequently outstripping the crude tools used at the bedside to measure blood glucose and to respond to its variation in concentration.

Software-driven insulin dosing is better than paperdriven insulin protocols. Software integrates all of the glucose measurements and all of the previous insulin adjustments to determine the next best insulin dose. Software appears to reduce glucose variability and to sustain glucose within the target range for prolonged periods of time [16]. There are now many software programs tested and/or available.

Handheld blood glucometers, originally intended for use by type I diabetic outpatients in the 1980s, are not accurate enough in the ICU environment [17], and are very laborious to use. In March 2010, the US Food and Drug Administration hosted a public inquiry into glucometers, and is now redefining what it will accept regarding accuracy of blood glucose measurement devices in the hospital setting [18]. The US Food and Drug Administration has asked the international standards body to reset its limits for accuracy for glucometers. Current-generation handheld devices now in use will not make the cut.

Finally, the more frequent the blood glucose measurement, even with handheld glucometers, the less hypoglycemia experienced by patients and the tighter the glycemic control [19]. The SPRINT study supports this premise. Frequency is crucial, however laborious it may be.

What can we expect going forward?

We can expect that the world will continue to use intensive insulin, but that the range defining tight glucose control will be narrowed as it becomes more achievable. We can expect that there will be more emphasis on defining hypoglycemia, and in avoiding it with greater rigor. We can expect a movement towards insulin-dosing software, as the development of many programs appears simple, and competition will force down the cost of purchase and use. Software insulin-dosing has hidden advantages: it forces more blood glucose monitoring and also provides an instant database for analysis. We will someday be using glucometers that are engineered to be more accurate, especially in the hypoglycemic range, avoiding pitfalls in today's instruments due to chemical interferences and specific disease conditions. Importantly, these devices will be continuous or near continuous, will push blood glucose information to the bedside nurse and by their nature will be less arduous. At the same time, manufacturers will need to make these devices affordable, or their uptake will be slowed. The greater frequency of blood glucose measurements by these devices will dramatically make safer the continuous administration of insulin.

Improving the accuracy of blood glucose measurements and standardizing the determination of insulin-dosing with better methods will produce better quality research, thereby synergizing global convergence on tight glycemic control, reduced glucose variability and better patient outcomes.

\section{Abbreviations}

ICU, intensive care unit; SPRINT, Specialised Relative Insulin and Nutrition Titration.

\section{Competing interests}

The author declares assistance from Optiscan and Echo Therapeutics.

\section{Published: 24 September 2010}

\section{References}

1. Chase JG, Pretty CG, Pfeifer L, Shaw GM, Preiser J-C, Le Compte AJ, Lin J, Hewett D, Moorhead KT, Desaive T: Organ failure and tight glycemic control in the SPRINT study. Crit Care 2010, 14:R154.

2. Van den Berghe $G$, Wouters P, Weekers F, Verwaest C, Bruyninckx F, Schetz M, Vlasselaers D, Ferdinande P, Lauwers P, Bouillon R: Intensive insulin therapy in critically ill patients. N Engl J Med 2001, 345:1359-1367.

3. Van den Berghe G, Wilmer A, Hermans G, Meersseman W, Wouters PJ, Milants I, Van Wijngaerden E, Bobbaers H, Bouillon R: Intensive insulin therapy in the medical ICU. N Engl J Med 2006, 354:449-461.

4. Krinsley JS: Effect of an intensive glucose management protocol on the mortality of critically ill adult patients. Mayo Clin Proc 2004, 79:992-1000.

6. Brunkhorst FM, Engel C, Bloos F, Meier-Hellmann A, Ragaller M, Weiler N, Moerer O, Gruendling M, Oppert M, Grond S, Olthoff D, Jaschinski U, John S, Rossaint R, Welte T, Schaefer M, Kern P, Kuhnt E, Kiehntopf M, Hartog C, Natanson C, Loeffler M, Reinhart K: Intensive insulin therapy and pentastarch resuscitation for severe sepsis. N Engl J Med 2008, 358:125-139.

6. Finfer S, Chittock DR, Su SY, Blair D, Foster D, Dhingra V, Dellomo R, Cook D, Dodek P, Henderson WR, Hébert PC, Heritier S, Heyland DK, McArthur C, McDonald E, Mitchell I, Myburgh JA, Norton R, Potter J, Robinson BG, Ronco $\mathrm{JJ}$ : Intensive versus conventional glucose control in critically ill patients. NEngl J Med 2009, 360:1283-1297.

7. Treggiara MM, Karir V, Yanez ND, Weiss NS, Daniel S, Deem SA: Intensive insulin therapy and mortality in critically ill patients. Crit Care 2008, 12:R29.

8. Annane D, Carlou A, Maxime V, Azoulay E, D'honneur G, Timsit JF, Cohen Y, Wolf M, Fartoukh M, Adrie C, Santré C, Bollaert PE, Mathonet A, Amathieu R, Tabah A, Clec'h C, Mayaud J, Lejeune J, Chevret S: Corticosteroid treatment and intensive insulin therapy for septic shock in adults: a randomized controlled trial. JAMA 2010, 303:341-348.

9. De la Rosa GDC, Donado JH, Restrepo AH, Quintero AM, González LG, Saldarriaga NE, Bedoya M, Toro JM, Velásquez JB, Valencia JC, Arango CM, Aleman PH, Vasquez EM, Chavarriaga JC, Yepes A, Pulido W, Cadavid CA: Strict glycaemic control in patients hospitalized in a mixed medical and surgical intensive care unit: a randomized clinical trial. Crit Care 2008, 12:R120.

10. Preiser JC, Devos P, Ruiz-Santana S, Mélot C, Annane D, Groeneveld J, lapichino G, Leverve X, Nitenberg G, Singer P, Wernerman J, Joannidis M, Stecher A, Chioléro R: A prospective randomized multi-centre controlled trial on tight glucose control by intensive insulin therapy in adult intensive care units: the Glucontrol study. Intensive Care Med 2009, 
35:1738-1748

11. Chase JG, Shaw G, Le Compte A, Lonergan T, Willacy M, Wong XW, Lin J, Lotz T, Lee D, Hann C: Implementation and evaluation of the SPRINT protocol for tight glycaemic control in critically ill patients: a clinical practice change. Crit Care 2008, 12:R49.

12. Nasraway SA: Sepsis research: we must change course. Crit Care Med 1999 , 27:427-430.

13. Falciglia M, Freyberg RW, Almenoff PL, D'Alessio DA, Render ML: Hyperglycemia-related mortality in critically ill patients varies with admission diagnosis. Crit Care Med 2009, 37:3001-3009.

14. Griesdale DEG, de Souza RJ, van Dam RM, Heyland DK, Cook DJ, Malhotra A Dhaliwal R, Henderson WR, Chittock DR, Finfer S, Talmor D: Intensive insulin therapy and mortality among critically ill patients: a meta-analysis including NICE-SUGAR study data. Can Med Assoc J 2009, 180:821-827.

15. Finney SJ, Zekveld C, Elia A, Evans TW: Glucose control and mortality in critically ill patients. JAMA 2003, 31:634-635.

16. Juneja R, Roudebush CP, Nasraway SA, Golas AA, Jacobi J, Carroll J, Nelson D, Abad VJ Flanders SJ: Computerized intensive insulin dosing can mitigate hypoglycemia and achieve tight glycemic control when glucose measurement is performed frequently and on time. Crit Care 2009, 13:R163.

17. Kanji S, Buffie J, Hutton B, Bunting PS, Singh A, McDonald K, Fergusson D, McIntyre LA, Hebert PC: Reliability of point-of-care testing for glucose measurement in critically ill adults. Crit Care Med 2005, 33:2778-2785.

18. FDA/CDRH Public Meeting: Blood Glucose Meters [http://www.fda.gov/ MedicalDevices/NewsEvents/WorkshopsConferences/ucm187406. htm\#transcripts]

19. Cook CB, Abad V, Kongable G, Hanseon Y, McMahon D: The status of glucose control in U.S. intensive care units [abstract]. Crit Care Med 2008, 36:sA68

doi:10.1186/cc9236

Cite this article as: Nasraway SA Jr, Rattan R: Tight glycemic control: what do we really know, and what should we expect? Critical Care 2010, 14:198. 